\title{
EDITORIAL
}

\section{The Editorial Advisory Board}

The editorial reviewing process of Protein Science, as of most scientific journals, relies on the experience and judgment of the Editorial Advisory Board whose members are chosen on the basis of their proven expertise in specific areas of research, their integrity and objectivity. An essential part of their duties is their willingness to respond promptly to requests for arbitration when a manuscript has received conflicting recommendations by the primary reviewers or when, in the judgment of the editors, a manuscript has not been adequately reviewed. Sometimes they are also called upon to advise on the appropriateness of manuscripts before they are submitted to the reviewing process. Board members also respond to appeals by authors whose manuscripts have been declined, and Board members themselves may act as primary reviewers. Although the involvement of a Board member in editorial decisions may prolong the reviewing process, in the end this procedure assures fairness and minimizes erroneous decisions. The end of the calendar year is a fitting occasion to remind authors and readers of the services rendered by members of the Editorial Advisory Board and to express our appreciation for their devotion to a difficult task.
Members of the Board are appointed for a limited term which initially was three to four years, and in the interest of rotation, has since been reduced to a two-year, renewable term.

At the end of 1995, the following Board members will retire:

William F. DeGrado, Kenneth Holmes, Gary Nelsestuen, Peter G. Schultz, Koiti Titani, Peter H. von Hippel and Peter Walter.

As of January 1, 1996, the following scientists will join the Editorial Advisory Board:

Judith S. Bond, Sadaaki Iwanaga and David Shortle.

We welcome them to the Board and look forward to benefiting from their experience and advice. Nominations of additional candidates are welcome and will receive careful consideration by the editors.

HANS NEURATH

\section{Go on-line with Protein Science}

Electronic Edition http://www.prosci.uci.edu 